\title{
$\mathrm{B}$

Boletim Científico do Instituta Agronômico do Estado de S. Paulo

Vol. 31

Campinas, agosto de 1972

N. ${ }^{0} 21$

\section{ESTUDOS DE COMPETIÇÃO ENTRE O ARROZ VERMELHO E O ARROZ CULTIVADO ( $\left.{ }^{1}\right)$}

Hermógenes de Freitas Leitão Filho $\left({ }^{2}\right)$, engenheiro-agrônomo, Seção de Botânica Econômica, N. V. Banzato $\left({ }^{2}\right)$ e L. E. Azzinr $\left({ }^{2}\right)$, engenheiros-agronômos, Seção de Genética, Instituto Agronômico, e Geraldo Guimarães, engenheito-agrônomo, Campo de Pesquisas do Serviço do Vale do Paraíba

\section{SINOPSE}

No presente estudo, conduzido em vasos, em casa de vegetação, procurou-se determinar os efeitos competitivos do arroz vermelho em relação ao cultivar IAC-435. Este, sob a referida competição, apresentou sensivel decréscimo do peso do sistema radicular e diminuição acentuada do número de perfilhos.

\section{1 - INTRODUÇÃO}

O problema das plantas invasoras é de transcendental importância em qualquer cultura, pois as reduções de rendimento, determinadas pela sua presença, são bastante ponderáveis e capazes de inutilizar o empreendimento agrícola. Enquanto a maioria das plantas pode ser controlada por processos químicos ou tratos culturais, algumas existem que, pela sua biologia ou pela sua morfologia, tornam-se dificilmente erradicáveis e muito mais problemáticas.

$\mathrm{O}$ arroz vermelho contitui-se numa das mais importantes plantas invasoras da cultura do arroz irrigado $(1-4)$. No Vale do Paraíba, no Estado de $\mathrm{S}$. Paulo, onde predomina essa modalidade de cultivo, essa invasora tem causado sensíveis decréscimos de rendi-

\footnotetext{
( ${ }^{1}$ ) Trabalho apresentado na XVII Reunião Anual da Sociedade Brasileira para o Progresso da Ciência, realizada em Salvador, Bahia, de 5 a 11 de julho de 1970 . Recebido para publicação em 28 de outubro de 1971.

${ }^{2}$ ) Com bolsa de suplementação do $\mathrm{CNPq}$.
} 
mentos, chegando, algumas vezes, a limitar a possibilidade de produção.

O arroz vermelho pertence à espécie botânica Oryza sativa L., à qual também pertence o arroz cultivado. Botanicamente pode-se considerar o arroz vermelho como uma variedade da espécie Oryza sativa L., a qual pode ser diferenciada, no campo, pela deiscência e pubescência das espiguetas e da lâmina foliar, maior perfilhamento e menor resistência ao acamamento.

Considerando a mesma identidade específica do arroz vermetho e do arroz cultivado, fica de pronto eliminada a possibilidade do controle químico da planta invasora durante o plantio do arroz cultivado.

Os problemas que o arroz vermelho ocasiona podem ser resumidos da seguinte forma:

a) No campo, o arroz vermelho sofre um processo de debulha natural. Uma vez maduros, os grãos caem ao solo. Na entre-safra o arroz vermelho germina muito pouco, ocorrendo a máxima germinação por ocasião do plantio do arroz cultivado. Por outro lado, sabe-se que cariopses de arroz vermelho sobrevivem no solo durante períodos longos de tempo ( $2-3$ anos), garantindo dessa forma a reinfestação dos plantios posteriores.

b) $\mathrm{O}$ arroz vermelho apresenta maior rusticidade que o cultivado, resistindo melhor às condições adversas do meio ambiente.

c) $\mathrm{O}$ arroz vermelho não tem tipo comercial. Lotes com porcentagens elevadas de arroz vermelho são bastante depreciados. Por outro lado, no arroz vermelho a lema e a pálea estão mais intimamente aderidas ao grão, fato que dificulta sobremaneira 0 seu beneficiamento, necessitando os órgãos de descasque maior aperto, o que ocasiona porcentagens elevadas de quebra dos grãos do arroz cultivado, depreciando dessa forma a qualidade do produto obtido.

d) Sementes obtidas de campos de cooperação que apresentam índices de arroz vermelho superiores a 20 por mil (mais de 30 grãos em 500 gramas da amostra) estão inutilizadas para distribuição aos agricultores.

e) $\mathrm{O}$ arroz vermelho, em condições normais de campo, cruza-se com o arroz cultivado, apresentando uma taxa de cruzamento ao redor de $4 \%$. Logo, umas poucas plantas de arroz vermelho flo- 
rescendo normalmente no campo podem originar uma população híbrida bastante numerosa, principalmente se for considerado que os caracteres mais danosos do arroz vermelho (cor do pericarpo vermelha, deiscência dos grãos, forte aderência da lema e da pálea e glumas pilosas) são dominantes.

f) Não oferece possibilidade de controle químico, pela sua extrema afinidade botânica com o arroz cultivado.

g) $\mathrm{O}$ arroz vermelho em geral é mais precoce que o arroz cultivado. Pela precocidade apresenta a maturação mais cedo, e sendo de fácil debulha cai frequientemente ao solo antes de ser colhido.

\section{2 - MATERIAIS E METODOS}

As sementes para os estudos competitivos entre o arroz vermelho e o arroz cultivado foram obtidas no Campo de Pesquisas do Serviço do Vale do Paraíba. As do arroz vermelho achavam-se misturadas com sementes de arroz preto em intensidades muito variáveis, mostrando uma segregação muito acentuada, como é indicado na relação dada a seguir, relativa à amostra do material colhido no ano agrícola de 1967/68, no referido campo experimental.

Variedade e mutante Arroz preto

típico . . . . . . . . . . . . . .

Sub-total Arroz vermelho

aristado

mútico de grãos curtos ........

mútico de grãos longos ......

Sub-total .

Total g

306,0

99,2

405,2

35,1

302,4

67,5

405,0

810,2
$\%$

37,77

12,24

50,01

Para o estudo, foi utilizada uma amostra de arroz vermelho não aristado (mútico), que apresentou mistura de grãos longos e curtos.

O ensaio foi desenvolvido em casa de vegetação, da Seção de Genética, Instituto Agronômico, com os plantios realizados em vasos cerâmicos de 28 × 29,5 cm durante os anos agrícolas de 1968 
e 1969. As plantas tiveram boas condições de adubação e irrigação, e também condições uniformes de luminosidade. Foram realizadas observações semanais, do plantio até o início do aparecimento das panículas. Durante o período de crescimento das panículas as observações foram diárias até à sua completa formação. A partir dessa data até à colheita das plantas as observaçóes foram semanais. Para comparação dos efeitos competitivos do arroz vermelho foi utilizado o cultivar IAC-435, largamente empregado em culturas irrigadas do Estado de S. Paulo.

O delineamento para a verificação dos efeitos competitivos obedeceu à seguinte esquematização.

\begin{tabular}{|c|c|c|}
\hline upo & I & $\begin{array}{l}1 \text { vaso }-1 \text { planta do } \mathrm{cv} \text { IAC- } 435 \\
1 \text { vaso }-1 \text { planta de arroz vermelho }\end{array}$ \\
\hline rupo & II & $\begin{array}{l}1 \text { vaso }-2 \text { plantas do } \mathrm{cv} \text { IAC- } 435 \\
1 \text { vaso }-2 \text { plantas de arroz vermelho }\end{array}$ \\
\hline rupo & III & $\begin{array}{l}1 \text { vaso }-3 \text { plantas de cv IAC- } 435 \\
1 \text { vaso }-3 \text { plantas de arroz vermelho }\end{array}$ \\
\hline rupo & IV & $\begin{aligned} 1 \text { vaso - } 1 \text { planta de arroz vermelho e } \\
1 \text { planta do cv IAC- } 435\end{aligned}$ \\
\hline 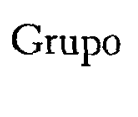 & $\mathrm{V}$ & $\begin{aligned} 1 \text { vaso }- & 2 \text { plantas de arroz vermelho } \\
& \text { l planta do cv IAC- } 435\end{aligned}$ \\
\hline
\end{tabular}

De cada grupo foram providas duas repetições.

Foram analisados os seguintes caracteres:

a - Altura das plantas - Para obtenção deste dado mediramse as alturas dos perfilhos úteis de cada planta adulta, após total desabrocho das panículas. A altura foi definida como a medida tomada do colo da planta até à base da panícula .

b - Número de perfilhos - Este valor foi obtido computando-se apenas os perfilhos úteis de cada planta (que apresentam inflorescência) .

c - Peso da parte aérea e peso das raízes - Valores obtidos após a colheita das plantas. Nesta ocasião foram realizadas as referidas observações, eliminando-se cuidadosamente a terra aderida às raízes.

d - Fertilidade das flores - Por ocasiáo do aparecimento das panículas foram realizadas observaçōes diárias para avaliação da fertilidade das flores. De cada planta foram marcadas 10 panículas, 
nas quais foram observados o desenvolvimento e a viabilidade de todas as flores.

e - Comprimento da panícula - Observação feita em 10 panículas por planta, completamente desenvolvidas.

$\mathrm{f}$ - Dimensões das cariopses - Foram computadas as seguintes medidas das cariopses: comprimento, largura, espessura, relação comprimento : largura e peso de 1000 grãos. As medições foram feitas em cariopses com e sem lema e pálea, realizando-se em cada caso 50 observaçōes.

\section{3 - RESULTADOS E CONCLUSÕES}

Os resultados foram condensados nos quadros 1 a 3 .

Quadro 1. - Resultados de ensaio em vasos, em casa de vegetação, para estudo da competiçāo entre arroz vermelho e arroz cultivado, em $1969 / 70$

\begin{tabular}{|c|c|c|c|c|}
\hline \multirow{2}{*}{ Tratamento } & \multicolumn{4}{|c|}{ Dados coletados (*) } \\
\hline & Raízes & $\begin{array}{c}\text { Parte } \\
\text { vegetativa }\end{array}$ & Perfilho & Altura \\
\hline Grupo I (1 planta por vaso) & $g$ & $g$ & $n .^{\circ}$ & $\mathrm{cm}$ \\
\hline Arroz vermelho $\ldots \ldots \ldots$ & 82,5 & 97,5 & 22,0 & 80,4 \\
\hline Arroz cultivado (**) $\ldots \ldots$ & 72,5 & 160,0 & 16,0 & 115,0 \\
\hline \multicolumn{5}{|l|}{ Grupo II ( 2 plantas por vaso) } \\
\hline Arroz vermelho & 38,8 & 67,5 & 14,5 & 80,5 \\
\hline Arroz cultivado .. & 57,5 & 91,3 & 11,8 & 99,0 \\
\hline \multicolumn{5}{|l|}{ Grupo III ( 3 plantas por vaso) } \\
\hline Arroz vermelho & 30,0 & 51,7 & 12,0 & 82,8 \\
\hline Arroz cultivado . & 46,7 & 65,8 & 8,7 & 98,0 \\
\hline \multicolumn{5}{|l|}{$\begin{array}{l}\text { Grupo IV (2 plantas } \\
\text { consorciadas) }\end{array}$} \\
\hline Arroz vermelho (1) ...... & 67,5 & 80,0 & 17,0 & 90,0 \\
\hline Arroz cultivado (1) $\ldots$. & 47,5 & 85,0 & 10,5 & 96,6 \\
\hline \multicolumn{5}{|l|}{$\begin{array}{l}\text { Grupo V ( } 3 \text { plantas } \\
\text { consorciadas) }\end{array}$} \\
\hline Arroz vermelho (2) & 40,0 & 50,0 & 13,5 & 82,3 \\
\hline Arroz cultivado (1) $\ldots$. & 27,5 & 45,0 & 7,0 & 101,0 \\
\hline
\end{tabular}

( *) Médias de 2 repetiçōes.

(**) cr. IAC-435. 
Analisando o quadro 1 , com referência ao peso das raízes infere-se o seguinte: a) com uma planta por vaso, o arroz vermelho desenvolveu um sistema radicular mais vigoroso que o arroz cultivado $(82,5 \mathrm{~g} \mathrm{X} 72,5 \mathrm{~g})$;

b) quando ocorrem duas ou três plantas por vaso, sem consorciação, nota-se que o arroz cultivado apresenta sistema radicular individual mais desenvolvido que o do arroz vermelho $(57,5 \mathrm{~g}$ X 38,8 g e 46,7 g X 30,0 g). Este fato pode ser explicado pela maior concorrência que duas ou três plantas de arroz vermelho exercem entre si;

c) quando existe consorciação, o efeito da concorrência que o arroz vermelho exerce sobre o cultivado é tal que determina um acúmulo do peso do seu sistema radicular de $38,8-\mathrm{g}$ para $67,5 \mathrm{~g}$ ) e um sensível decréscimo do peso do sistema radicular do arroz cultivado (de $57,5 \mathrm{~g}$ para $47,5 \mathrm{~g}$ ). Quando se coloca uma planta de arroz vermelho consorciada com uma planta de arroz cultivado, o efeito da concorrência acentua-se sobremaneira (no arroz cultivado o peso cai de $46,7 \mathrm{~g}$ para $27,5 \mathrm{~g}$ ).

Com base na análise do peso da parte vegetativa, verifica-se o seguinte:

a) sem consorciação, o arroz cultivado apresenta-se com um peso da parte vegetativa maior que o do arroz vermelho. Isto pode ser explicado pela sua maior altura e presença de maior quantidade de elementos lenhosos em seu colmo. Este último fato é facilmente constatável no cultivar IAC-435, que se apresenta menos sujeito ao acamamento e à quebra dos internódios que o arroz vermelho;

b) em consorciação, nota-se tendência para equilíbrio dos pesos das partes vegetativas $(85,0 \times 80,0$ para consorciação $1 \mathrm{X} 1$, e 45,0 X 50,0 no caso de consorciação $2 \times 1$ ). Tal fato é explicado pela pesada concorrência exercida pelo arroz vermelho, que reduz muito o sistema radicular do arroz cultivado, não permitindo desenvolvimento normal da parte aérea.

Quanto ao número de perfilhos, constata-se que:

a) o arroz vermelho apresenta-se com perfilhamento mais intenso que o arroz cultivado, isoladamente ou consorciado;

b) em consorciação ocorre acentuada redução no número de perfilhos do arroz cultivado, explicável pela redução do sistema radicular, devido à concorrência do arroz vermelho. 
LEITÃo \& OUTROS

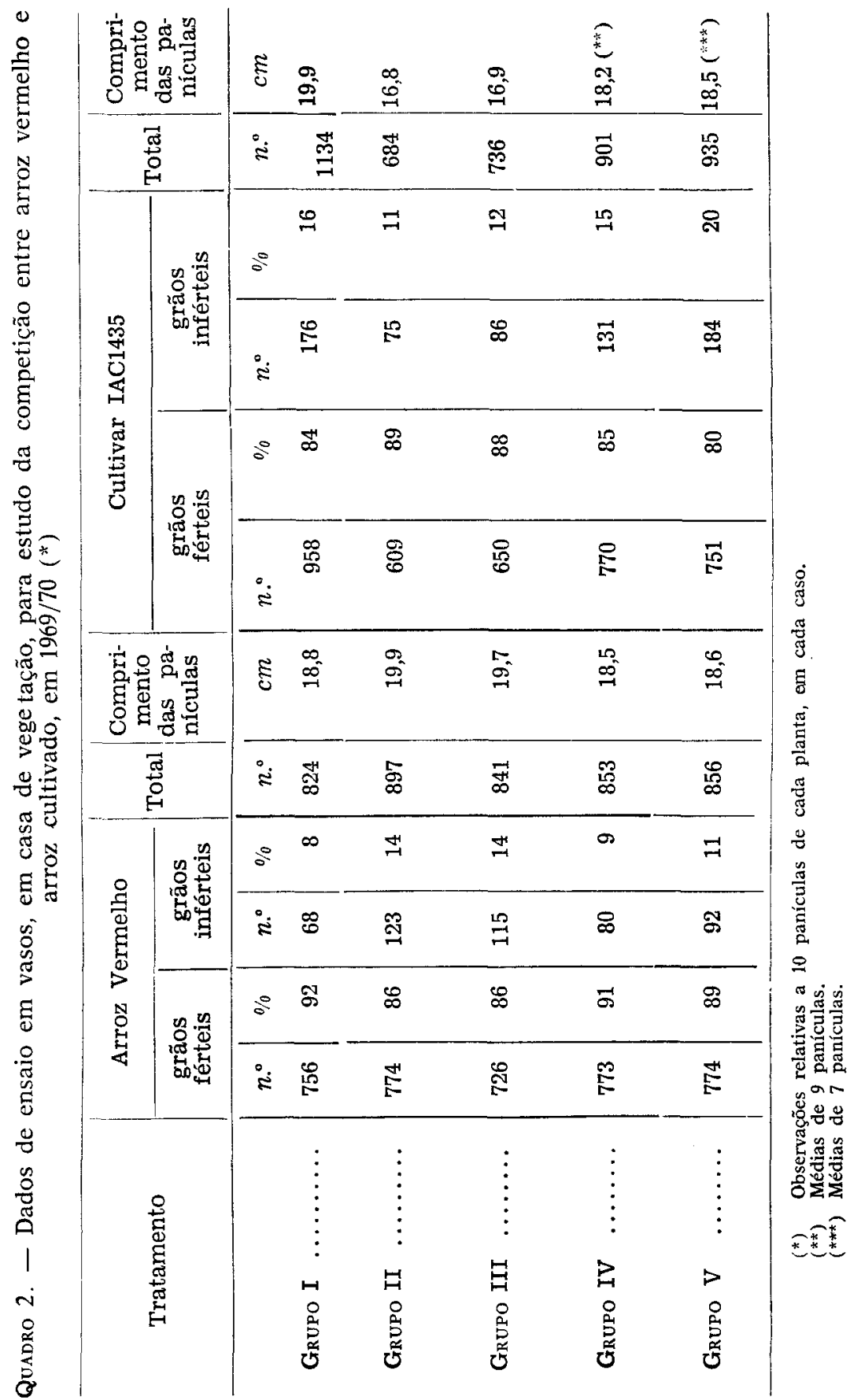


Com referência à altura das plantas, infere-se que: melho;

a) o cultivar IAC-435 foi sempre mais alto que o arroz ver-

b) em consorciação, tal fato permaneceu constante, com a planta diminuindo o peso do sistema radicular e número de perfilhos, mas mostrando altura mais elevada que a do arroz vermelho, como meio de sobrevivência.

Analisando o quadro 2, referente ao estudo de 10 panículas de cada classe examinada, conclui-se:

a) no arroz cultivado a produção de cariopses foi maior quando se teve uma única planta isolada, que se apresentava vigorosa e com perfilhamento não muito grande, permitindo a formação de panículas longas e produtivas, embora com porcentagem maior de espiguetas inférteis. Quando houve concorrência entre plantas de arroz cultivado, ocorreu diminuição no número de cariopses formadas e redução no comprimento das panículas. No arroz vermelho não se notaram diferenças significativas entre os diversos tratamentos;

b) em consorciação o arroz cultivado apresentou um número total de grãos bastante elevado. Pela concorrência, o arroz cultivado produziu plantas com poucos perfilhos, bastante altas e com poucas panículas longas e produtivas. $\mathrm{O}$ arroz vermelho não apresentou alterações significativas pela consorciação.

c) No arroz vermelho a porcentagem de grãos inférteis obedeceu à seguinte variação: com uma única planta, teve-se baixa porcentagem de grãos inférteis $(8 \%)$. Quando houve concorrência de duas ou três plantas, a porcentagem de grãos inférteis aumentou para $14 \%$. Existindo consorciação na base de 1 X l, a porcentagem de grãos inférteis do arroz vermelho foi de $9 \%$, pois o arroz cultivado prejudicou muito pouco a sua granação. No caso de consorciação 2 X 1 houve ligeiro aumento de porcentagem de grãos inférteis, explicável pela concorrência exercida pelas duas plantas de arroz vermelho.

d) $\mathrm{O}$ arroz cultivado, quanto à fertilidade de suas flores, obedeceu à seguinte variação:

Com uma única planta isolada, a porcentagem de espiguetas inférteis foi relativamente alta (16\%), explicável pelo grande número de espiguetas que as panículas apresentavam. Existindo a 
concorrência de duas e três plantas, houve diminuição no número de espiguetas por panícula e na porcentagem de espiguetas inférteis.

Havendo consorciação, a pesada concorrência exercida pelo arroz vermelho forçou a formação de plantas de arroz cultivado elevadas e pouco perfilhadas, com escasso sistema radicular. As panículas apresentavam-se relativamente bem desenvolvidas, com numerosas espiguetas, mas com porcentagem relativamente alta de espiguetas inférteis, pela ação da concorrência. Nota-se, portanto, que, sob consorciação, o arroz cultivado produz poucas panículas de comportamento aproximadamente semelhante ao de uma planta isolada.

Quadro 3. - Caracteres biométricos de cariopses do arroz vermelho e do cv IAC-435, anotados em ensaio em vasos, em casa de vegetação, para estudo da competição entre as citadas variedades, em 1969/70 (*)

\begin{tabular}{|c|c|c|c|c|c|c|}
\hline \multirow{3}{*}{$\begin{array}{c}\text { Caracteres } \\
\text { das } \\
\text { cariopses }\end{array}$} & \multicolumn{3}{|c|}{ Arroz Vermelho } & \multicolumn{3}{|c|}{ Arroz Cultivado } \\
\hline & \multirow[t]{2}{*}{$\mathrm{c} / \mathrm{casca}$} & \multirow[t]{2}{*}{ s/ casca } & \multirow{2}{*}{$\begin{array}{l}\text { Relação } \\
\text { s/casca } \\
\text { c/casca }\end{array}$} & \multirow[t]{2}{*}{ c/ casca } & \multirow[t]{2}{*}{ s/ casca } & $\begin{array}{l}\text { Relação } \\
\text { s/casca }\end{array}$ \\
\hline & & & & & & c/casca \\
\hline & & & $\%$ & & & $\%$ \\
\hline Comprimento ( $\mathrm{mm}$ ) & 8,23 & 6,00 & 73 & 9,72 & 7,32 & 75 \\
\hline Largura $(\mathrm{mm})$ & 3,04 & 2,73 & 90 & 2,76 & 2,54 & 92 \\
\hline Espessura (mm) & 2,32 & 2,13 & 92 & 2,22 & 2,01 & 91 \\
\hline $\begin{array}{l}\text { Relação compr./ } \\
\text { largura } \ldots . . . .\end{array}$ & 2,71 & 2,19 & 81 & 3,52 & 2,88 & 82 \\
\hline $\begin{array}{l}\text { Peso de } 1000 \text { unida- } \\
\text { des }(\mathrm{g}) \ldots \ldots \ldots\end{array}$ & 30,00 & - & 一 & 34,00 & 一 & - \\
\hline
\end{tabular}

(*) Medias de 5io observações.

Os dados biométricos obtidos e condensados no quadro 3 mostram que o arroz vermelho apresenta menor comprimento que o cultivado e com maior largura dos seus grãos, o que lhe dá uma relação comprimento/largura mais baixa que o cultivado, podendo ser incluílo na classe "meio agulha". Nesta classificação considera-se o comprimento e a relação comprimento/largura dos grãos sem casca e da seguinte maneira: 
Tipos

Agulha $\ldots \ldots \ldots$.

Meio Agulha ....

Cateto ..........
Comprimento Relação Compr/Larg. maior $\mathrm{mm}$

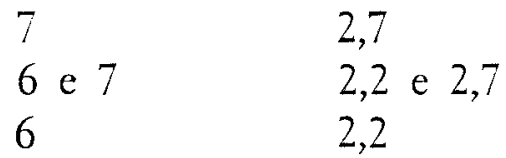

Pela mesma classificação o cultivar IAC-435 é enquadrado no tipo agulha.

As relações em. porcentagens, obtidas para os diferentes caracteres biométricos dos grãos com casca e sem casca, mostram que o arroz vermelho e o cultivado as têm muito semelhantes, o que indica pertencerem ambos à mesma espécie de Oryza.

COMPARATIVE STUDIES ON THE COMPETITION BETWEEN RED RICE AND CULTIVATED RICE

\section{SUMMARY}

The present study was conducted in greenhouse, in order to evaluate the competition between red rice and the cultivar IAC-435. The effect of competition was measured on the root and aerial development (tillering, height of plants and fertility of panicles). The principal effects of competition were observed in the weight of root development and number of tillers of the cultivated rice IAC-435, that suffered great reduction in account of concurrence determined by the red rice.

\section{LITERATURA CITADA}

1. INSTITUTO RIOGRANDENSE DO ARROZ. Regulamento para a produção de semente de arroz. Porto Alegre, 1967. $11 \mathrm{p}$.

2. SMITH, J. R. \& SHAW, C. W. Weeds and their control in rice production. Washington, Departament of Agriculture, 1966. 64p. (Agriculture Handbook 292)

3. SONNIER, E. A. Red rice studies. In: LOUISIANA. Rice Experiment Station. 57th annual progress report. Crowley, 1965. p. 114-125.

4. - Red rice studies. In: LOUISIANA. Rice Experiment Station. 58th annual progress report. Crowley, 1966. p. 19-28. 